\title{
Effects of Plyometric Training on Technical Skill Performance of Handball Team Players at Debre Markos Town
}

\author{
Wubliker Tibebu Guadie \\ Department of Sport Science, Debre Markos University, Debre Markos, Ethiopia \\ Email address: \\ wubliker3138@gmail.com
}

To cite this article:

Wubliker Tibebu Guadie. Effects of Plyometric Training on Technical Skill Performance of Handball Team Players at Debre Markos Town. International Journal of Sports Science and Physical Education. Vol. 6, No. 3, 2021, pp. 41-47. doi: 10.11648/j.ijsspe.20210603.11

Received: June 26, 2021; Accepted: July 14, 2021; Published: July 29, 2021

\begin{abstract}
The purpose of this study was to examine effects of twelve weeks plyometric training on technical skill performance of handball players in Debre Markos handball team players. The total subject for the study were twenty-two $(n=22)$ male handball trainees of Debre Markos handball team players in 2019/2020. The study populations were little; all were taken as a sample by using comprehensive sampling technique. Through randomization method trainees segregated in to two groups, an experimental group ( $\mathrm{n}=11$ ) and a control group $(\mathrm{n}=11)$. The experimental group (EG) performed a twelve-week plyometric exercise, 3-days per week for a total of 60 minutes per day and the control group (CG) did not perform any plyometric exercise that designed for this study. To achieve the objective of this study, quantitative research approach and True experimental research design was utilized. The data was collected through field technical skill test of study participants and this data were analyzed by using Paired sample ttest and Independent sample t-test statistical tools. Based on the data analyzed, the pre-posttest performance of EG were significantly improved in shooting accuracy and speed dribbling dependent variables ( $\mathrm{SA}, \mathrm{P}=0.000, \mathrm{SD}, \mathrm{P}=0.002, \mathrm{p}<0.05$ ), but passing accuracy was not improved at the level of significance $(\mathrm{P}=0.457, \mathrm{p}>0.05)$; similarly, the independent $\mathrm{t}$-test shows the posttest performance of shooting accuracy and speed dribbling of EG where significantly more improved than posttest CG group tests ( $\mathrm{SA}, \mathrm{P}=0.011, \mathrm{SD}, \mathrm{P}=0.007, \mathrm{p}<0.05)$, but not in passing accuracy $(\mathrm{P}=0.623, \mathrm{p}>0.05)$. The results of this study show that plyometric training improves shooting accuracy and speed dribbling of handball team player's technical skill performance, whereas plyometric training has not improved passing accuracy technical skill performance of handball team players. Based on the result and conclusion of the study recommendation will be forwarded for the concerned bodies.
\end{abstract}

Keywords: Plyometric Training, Shooting Accuracy, Passing Accuracy, Speed Dribbling, Technical Skill Performance

\section{Introduction}

\subsection{Background}

Sport is all forms of competitive physical activity or game which have its own rule and regulation. Ball sports like basketball, football, and handball are very popular sports in the world that includes a lot of different movements [11] One branch of sport, handball, attracts great attention and generates international excitement, contributing to tourism and uniting people across different countries [9] Handball is a team sport which is played by two teams of seven players each passes a ball to shot it into the goal of the opponent team. The objective is to score more goals by shooting the ball past a goalkeeper into the net [4].

Handball consists of physical fitness parameters that are strength, speed, endurance, jumping ability, and technical skills that are throwing, passing, dribbling and shooting [23]. The combination of technical skills, tactics, and physical parameters makes this sport very attractive but tough to play. Several studies have reported that, in handball, technical skills, tactics, and physical parameters constitute the determining factors for competitive success [20].

So, handball is a game that demands a high standard of physical fitness, mastering of techniques, and tactics. Handball require various fundamental technical skill performances of players like player's stance, ball holding, passing, dribbling, shooting, pivoting, screening, and defense. These technical 
skill performances are performed in the game both in an attacking and defensive movements and have to be performed quickly to beat an opponent player [2].

Several characteristics have been associated with unsuccessful technical skill performance rates in Debre Markos town handball team players. Apart from these, one aspect that has been shown to have a consistent relationship with technical skill performance that determines successful playing in handball is shooting accuracy [5]. In this regard, some previous studies have shown the importance of shooting accuracy in distinguishing winning and losing handball team [12]. Even though, to achieve a high shooting percentage and win a game, every team has to have players who can accurately shot in all periods of the game and under different physiological or psychological pressures. Consequently, it can be said that shooting accuracy is one of the most important technical skills in handball [13].

Another variable that can potentially affect the technical skill performance difference in handball team players is passing accuracy. It involves passing the ball to a teammate accurately. Several investigators have studied that, it is important that players are taught to know where their teammates are by constantly looking and coaches should teach players to provide intelligent verbal cues to help with decision-making in passing [18].

Yet, still another important variable that has a profound influence to contribute to technical skill performance in handball is speed dribbling. Concerning speed dribbling, [17] contended that speed dribbling helps a player to move with the ball towards the opponent's goal under the control of the ball within the free space. Similarly, speed dribbling in handball is the skill of running as fast as possible while keeping the ball out in front, available to be closely controlled by the dribbler. Moreover, it is used offensively when there is a clear free space. It helps a player to move with the ball through open space [17].

Over the past few years, various training methods have been used by different researchers and trainers to improve the technical skill performance of handball players [8]. In connection with this, a key significant problem that has been given limited consideration is the perception and interpretation of the plyometric training that has a great effect to improve the technical skill performance of handball players [10]. Correspondingly, to improve their technical skill performance, elite handball players must engage in specific conditioning, resistance, sprint, plyometric, and endurance training [20]. Among these various training methods, plyometric training the one which includes some of the prevalent sport moves such as jumping, skipping, and throwing.

Plyometric training involves exercises that generate quick, powerful movements involving explosive concentric muscle contraction followed by eccentric muscle action. Researchers have shown that plyometric training, when used can contribute to improvements in vertical jump performance, acceleration, leg strength, and muscular power [10]. But, the effect of plyometric training related to the successful technical skill performance of handball players remains to be a challenging task for coaches and researchers. Plyometric training along with elevated technical skill performance was considered to the major factor leading to positive accomplishments of each handball team player throughout the competition season. However, there is still unconcluded interest among researchers as to what extent plyometric training better improve the technical skill performance of handball team players. Therefore, the purpose of this study was to examine the effect of plyometric training on technical skill performance of handball players at Debre Markos handball team players.

\subsection{Statement of the Problem}

Handball is a very attractive modern sport with fast and exciting action. Successful performance in handball requires good technical skills to be successful in the competition [20]. Some different researchers are paying attention to the effects of plyometric training on technical skill performance in team sports. For instance, [1]. conducted a study on the effect of plyometric training on shooting accuracy and dribbling skill performance of soccer players. However, as to the knowledge of the investigator of this study is concerned, no or little research investigation has been conducted on these variables or insufficient at a handball team level in Debre Markos Town. It is; therefore, highly indispensable to make a closer investigation as to how this variable affects technical skill performance of handball team players at Debre Markos, Ethiopia.

Following this, [21] conduct a study on the effect of Plyometric exercise on shooting accuracy of handball payers and proved that plyometric training has no significant effect on shooting accuracy. On the contrary, [16]. study the effects of the plyometric training program on jumping and shooting accuracy of handball players and proved that plyometric training had a significant effect on jumping and shooting accuracy of handball players. These two previous research works indicated that there is a controversial research issue about the effect of plyometric training on shooting accuracy of handball players. Subsequently, Yahya and his colloquies and Surendra had not respectively shown whether or not plyometric training has an effect on passing accuracy and speed dribbling of handball teams. Thus, this study would be conducted to fill the gap of two previous researchers finding.

In addition, [15] conducted a study on the effect of plyometric training on selected physical fitness and skill performance variables of intercollegiate level men handball players. The study was conducted on passing accuracy, speed dribbling, and speed pass ability of handball players. As the researcher said that plyometric training group had no significantly improved speed dribbling and passing accuracy of intercollegiate level men handball players due to the effect of plyometric training program. Nonetheless, the recent research work of [3] conducted a study on the impact of plyometric exercises in the development of explosive power and some basic skills of handball players. Hence, plyometric exercises had significantly developed the level of performance of passing accuracy, receiving, speed dribbling, and jumping skill of handball players. However, this previous research 
works also ignored the effect of plyometric training on shooting accuracy of handball team players. Therefore, to fill the gap of the above two researchers' results, this study was conducted on the effect of plyometric training on shooting accuracy, passing accuracy, speed dribbling of handball team players at Debre Markos town.

Though, generally, in Ethiopia, research into plyometric training in relation to speed dribbling, passing accuracy, and shooting accuracy of handball team players are scant compared to the multifarious problems widely observed in the context. Despite the extensiveness of the problem, this study looked into the plyometric training in relation to speed dribbling, passing accuracy and shooting accuracy in Ethiopia especially in Amhara Regional State, in Debre Markos town handball team players as a focal point, there is a very little study conducted on the effect of plyometric training on technical skill performance of handball players. For the reason that, the current research is to bridge the gap by examining in detail the effects of plyometric training on the technical skill performance of handball players at Debre Markos handball team players.

\subsection{Research Hypotheses}

This thesis had the following research hypotheses: -

Ho.1: Plyometric training has no significant effect on shooting accuracy of handball team players.

Ho.2: Plyometric training has no significant effect on speed dribbling of handball team players.

Ho.3: Plyometric training has no significant effect on passing accuracy of handball team players.

\subsection{Objectives of the Study}

\subsubsection{General Objective}

The general objective of the study was to scrutinize the effects of plyometric training on technical skill performance of handball team players in case of Debre Markos town handball team.

\subsubsection{Specific Objectives}

In line with the general objective, this study was organized under the following specific objectives.

1) To examine the effect of plyometric training on shooting accuracy of handball team players at Debre Markos Town.

2) To identify the effect of plyometric training on speed dribbling of handball team players at Debre Markos Town.

3) To determine the effect of plyometric training on passing accuracy of handball team players at Debre Markos Town.

\subsection{Significance of the Study}

This study provides different information for the concerned bodies such as, coaches, trainees, and other researchers who are motivated to research this area. So, the findings of this study may have a great contribution to add new ideas to the existing knowledge of the coach to design appropriate training program. In addition to this, the study could help the trainees as well as the coach to know their skill level and whether this training method develop their technical skill performance or not. Moreover, this study provides avail baseline information and reference data on effects of plyometric training on technical skill performance of handball players for coaches, instructors, and trainees. Furthermore, since there is a scarcity of research study on handball sport in Ethiopia and abroad, the findings of this study would be reference materials and provides evidence for future researchers on the same title in different perspectives.

\section{Research Methods}

\subsection{Research Design}

The research approach that this study used quantitative type of research approach. And, to achieve the objective of this study, a true experimental research design was utilized. There were both experimental and control groups in this study. Both groups were used for providing pre-test and post-test to identify the effects of plyometric training on the technical skill performance of Debre Markos town handball team players.

\subsection{Population, Sample and Sampling Techniques}

At Debre Markos town there were two handball teams, the male and female handball teams. But, the researcher has purposively selected the male handball team. So, the target population of this study was male handball players who found at Debre Markos handball team. The total numbers of players found at this team were 22. All were males and the populations were little in number, all players were taken as a sample by utilizing comprehensive sampling technique. These research participants were randomly assigned to the control and experimental group.

\subsection{Data Collection Instruments}

Since the research design was a true experimental research design, the data was collected through field skill test of study participants. So the data was collected through field tests of shooting accuracy, passing accuracy, and speed dribbling of handball players at Debre Markos handball team players. The data collection instruments designed by adapting skill test from researchers Umeshraj and Yogesh that already checked the validity and reliability of front shoot test from $9 \mathrm{~m}$ for shooting accuracy, accuracy throw test from 15 for passing accuracy and $6.1 \mathrm{~m}$ agility, or obstacle dribbling test for speed dribbling $[19,22]$.

\subsection{Training Protocol}

After doing 10 minute warming up the experimental group did Plyometric exercise that was given for 12 weeks three days per week for 60 minute in each day. After doing the plyometric exercise, they also perform cooling down exercise. 
Table 1. Training program for intervention.

\begin{tabular}{|c|c|c|c|c|c|c|c|}
\hline Week & Exercise & Set & Rep. & Rest sets (sec.) & Rest in exercise (sec.) & Vol. & intensity \\
\hline \multirow{5}{*}{$1-2$} & Squat jump & 3 & 6 & & & \multirow{5}{*}{68} & Low \\
\hline & Split squat jump & 3 & 6 & 3 & 30 & & Low \\
\hline & Wall clap push ups & 3 & 6 & & \multirow{3}{*}{60} & & low \\
\hline & Zig zag hop & 2 & 6 & \multirow{2}{*}{5} & & & Moderate \\
\hline & Clapping push up & 2 & 6 & & & & Moderate \\
\hline \multirow{5}{*}{$3-4$} & Squat jump & 2 & 10 & \multirow{2}{*}{3} & \multirow{2}{*}{30} & \multirow{5}{*}{80} & Low \\
\hline & Split squat jump & 2 & 10 & & & & Low \\
\hline & Clapping push ups & 2 & 7 & \multirow{2}{*}{5} & \multirow{2}{*}{60} & & Moderate \\
\hline & Zig zag hop & 2 & 7 & & & & Moderate \\
\hline & Depth push up & 2 & 6 & 10 & 120 & & High \\
\hline \multirow{5}{*}{$5-6$} & Squat jump & 3 & 7 & \multirow{2}{*}{3} & \multirow{2}{*}{30} & \multirow{5}{*}{86} & Low \\
\hline & Split squat jump & 3 & 7 & & & & Low \\
\hline & Clapping push ups & 2 & 8 & \multirow{2}{*}{5} & \multirow{2}{*}{60} & & Moderate \\
\hline & Zig zag hop & 2 & 8 & & & & Moderate \\
\hline & Depth push up & 2 & 7 & 10 & 120 & & High \\
\hline \multirow{5}{*}{$7-8$} & Squat jump & 4 & 6 & \multirow{2}{*}{3} & \multirow{2}{*}{30} & \multirow{5}{*}{100} & Low \\
\hline & Split squat jump & 4 & 6 & & & & Low \\
\hline & Clapping push ups & 3 & 6 & \multirow[b]{2}{*}{5} & \multirow{2}{*}{60} & & Moderate \\
\hline & Zig zag hop & 3 & 6 & & & & Moderate \\
\hline & Depth push up & 2 & 8 & 10 & 120 & & High \\
\hline \multirow{9}{*}{$9-10$} & Squat jump & 3 & 7 & \multirow{2}{*}{3} & \multirow{2}{*}{30} & \multirow{9}{*}{86} & Low \\
\hline & Split squat jump & 3 & 7 & & & & Low \\
\hline & Clapping push ups & 2 & 8 & \multirow{2}{*}{5} & \multirow{2}{*}{60} & & Moderate \\
\hline & Zig zag hop & 2 & 8 & & & & Moderate \\
\hline & Single leg vertical jump & 2 & 7 & 10 & 120 & & High \\
\hline & Split squat jump & 2 & 10 & & \multirow{4}{*}{$\begin{array}{l}60 \\
120\end{array}$} & & Low \\
\hline & Clapping push ups & 2 & 7 & & & & Moderate \\
\hline & Zig zag hop & 2 & 7 & 5 & & & Moderate \\
\hline & Single leg vertical jump & 2 & 6 & 10 & & & High \\
\hline
\end{tabular}

Adapted from: Kavitha (2016), Singh (2015), Wathen (2013) and Ezhilmaran (2016).

\subsection{Methods of Data Analysis}

For this study, the researcher was used mean and standard deviation statistical data analysis tools. Coupled with, paired Samples t-Test data analysis method would be used to compare between pre-test and post-test results of technical skill performance of handball players of both group and independent t-test would be used to compare the pretest and posttest mean value of experimental group with the control group. The data that was collected through field tests would be analyzed by using computerized Statistical Package for Social Sciences software (SPSS) version 23 was used. The level of statistical significance for the study was set at $\mathrm{p} \leq 0.05$.

\section{Results}

The purpose of this study was to examine the effect of plyometric training on shooting accuracy, passing accuracy and speed dribbling of handball players at Debre Markos handball team players. To do this, paired sample t-test and independent sample t-test computed and the results presented in tables 1 and 2 respectively.

Table 2. Computation of speed dribbling, shooting accuracy and passing accuracy of experimental and control groups between pre and posttests of men handball players.

\begin{tabular}{|c|c|c|c|c|c|}
\hline Variable & Group & Test & Mean & SD & Sig \\
\hline \multirow{4}{*}{ Speed dribbling } & \multirow{2}{*}{ Experimental group } & Pre test & 10.369 & .471 & \multirow{2}{*}{0.02} \\
\hline & & Post test & 9.3109 & .682 & \\
\hline & \multirow{2}{*}{ Control group } & Pre test & 10.51 & .521 & \multirow{2}{*}{0.032} \\
\hline & & Post test & 10.20 & .696 & \\
\hline \multirow{4}{*}{ Shooting accuracy } & \multirow{2}{*}{ Experimental group } & Pre test & 21.55 & 3.267 & \multirow{2}{*}{.000} \\
\hline & & Post test & 25 & 3.661 & \\
\hline & \multirow{2}{*}{ Control group } & Pre test & 21.73 & 2.687 & \multirow{2}{*}{0.395} \\
\hline & & Post test & 21.27 & 2.453 & \\
\hline \multirow{4}{*}{ Passing accuracy } & \multirow{2}{*}{ Experimental group } & Pre test & 18.18 & 2.714 & \multirow{2}{*}{.457} \\
\hline & & Post test & 18.82 & 1.834 & \\
\hline & \multirow{2}{*}{ Control group } & Pre test & 18.55 & 2.067 & \multirow[b]{2}{*}{0.152} \\
\hline & & Post test & 19.18 & 1.537 & \\
\hline
\end{tabular}

*. The mean difference is significant at the 0.05 level $\mathrm{df}=10$. 
As the above table 1 indicates that the mean values of handball skill variables with regard to the experimental group were 10.369 and 9.3109 for speed dribbling and the standard deviation was .471 and .682 of pre and posttest respectively. On the other side, in the case of shooting accuracy, the mean values and standard deviation values were 21.55 and 25 and 3.267 and 3.661 of pre and posttest respectively. And also the mean and standard deviation values of passing accuracy 18.18 and 18.82 and 2.714 and 1.834 of pre and posttest respectively. The p-value of speed dribbling of the experimental group was .002, for shooting accuracy was .000 , and passing accuracy was .457 . The findings of the study revealed that $E G$ significantly improved speed dribbling and shooting accuracy $(P<0.05)$, but has no significant improvement on passing accuracy was observed in between pre- and post-testing $(P>0.05)$.

And also, as the above table 1 indicates that the mean values of technical skill variables of handball with regard to the control group were 10.51 and 10.20 for speed dribbling and the standard deviation was .521 and .696 of pretest and posttest respectively. On the other side, in the case of shooting accuracy, the mean values and standard deviation values were 21.73 and 21.27 and 2.687 and 2.453 of pretest and posttest respectively. And also the mean values and standard deviation values of passing accuracy were 18.55 and 19.18 and 2.067 and 1.537 of pretest and posttest respectively. The p-value of speed dribbling, shooting accuracy, and passing accuracy were $0.032,0.395$, and 0.152 respectively. The findings of the study indicated that $C G$ has no significantly improved passing accuracy and shooting accuracy between pre and post-testing $(P>0.05)$, but has a slight improvement in speed dribbling between pre and posttesting $(p<0.05)$.

Table 3. Computation of speed dribbling, shooting accuracy and passing accuracy between experimental and control groups between men handball players.

\begin{tabular}{|c|c|c|c|c|c|c|c|}
\hline \multirow{2}{*}{ Variable } & \multirow{2}{*}{ Group } & \multicolumn{2}{|l|}{ Mean } & \multicolumn{2}{|c|}{ Standard deviation } & \multicolumn{2}{|l|}{ Sig } \\
\hline & & Pre test & Post test & Pre test & Post test & Pre test & Post test \\
\hline \multirow{2}{*}{$\begin{array}{l}\text { Speed } \\
\text { dribbling }\end{array}$} & Experimental group & 10.369 & 9.31 & .471 & .682 & \multirow{2}{*}{.514} & \multirow{2}{*}{.007} \\
\hline & Control group & 10.51 & 10.20 & .521 & .695 & & \\
\hline \multirow{2}{*}{$\begin{array}{l}\text { Shooting } \\
\text { accuracy }\end{array}$} & Experimental group & 21.55 & 25 & 3.267 & 3.66 & \multirow{2}{*}{.888} & \multirow{2}{*}{.011} \\
\hline & Control group & 21.73 & 21.27 & 2.687 & 2.453 & & \\
\hline \multirow{2}{*}{$\begin{array}{l}\text { Passing } \\
\text { accuracy }\end{array}$} & Experimental group & 18.18 & 18.82 & 2.714 & 1.834 & \multirow{2}{*}{.727} & \multirow{2}{*}{.623} \\
\hline & Control group & 18.55 & 19.18 & 2.067 & 1.537 & & \\
\hline
\end{tabular}

*. The mean difference is significant at the 0.05 level $\mathrm{df}=20$.

As the above table 2, indicates that the mean values of handball skill variables with regard to experimental and control group were 10.369 and 10.51 for speed dribbling and the standard deviation was .471 and .521 respectively. On the other side in case of shooting accuracy, the mean values of the experimental and control group were 21.55 and 21.73 and the standard deviation values are 3.267 and 2.687 respectively. And also the mean values experimental and control groups were 18.18 and 18.55 and standard deviation values of passing accuracy 2.714 and 2.067 respectively. The p-value of speed dribbling of was .514, for shooting accuracy was .888 and for passing accuracy was .727 . The findings of the study show that EG and CG have no significant difference in speed dribbling, passing accuracy and shooting accuracy observed in pre-testing $(\mathrm{P}>0.05)$.

As the above table 2, indicates that the mean values of handball skill variables of the experimental and control group were 9.31 and 10.20 for speed dribbling and the standard deviation was .682 and .695 respectively. On the other side in case of shooting accuracy, the mean values of the experimental and control group were 25 and 21.27 and the standard deviation values were 3.66 and 2.453 respectively. And also the mean values of experimental and control groups were 18.82 and 19.18 and standard deviation values of passing accuracy 1.834 and 1.537 respectively.

The p-value of speed dribbling was .007 , for shooting accuracy was .011 and for passing accuracy was 0.623 . The findings of the study presented that EG significantly improved speed dribbling and shooting accuracy than CG in post-testing $(P<0.05)$, but there is no significant improvement in passing accuracy was observed between EG and $\mathrm{CG}$ in post-testing $(P>0.05)$.

\section{Discussions}

This paper aimed to examine the effects of 12-weeks PT on the technical skill performance of handball players. The first purpose of this study was to examine the effect of plyometric training on shooting accuracy. To do this, paired sample t-test and independent sample t-test computed and the results of paired sample t-test demonstrated that EG significantly improved in shooting accuracy, but in the $C G$ indicated that no significantly improved in shooting accuracy observed in between pre-and post-testing. As a result of the independent sample t-test indicated that EG significantly improved than $\mathrm{CG}$ as observed in post-testing. In relation to this, the data which has been found from the present study is compatible with research findings such as; Gursharan showed that the effect of 12 weeks SAQ training has a significant effect on shooting accuracy of handball players [7]. Likewise, Surendra (2018) stated that plyometric training had a significant effect on jumping and shooting accuracy of handball players. On the contrary, Yahya et al. (2014) show that plyometric training has no significant effect on shooting accuracy.

The other objective of this study was to identify the effect 
of plyometric training on speed dribbling. To do this, paired sample t-test and independent sample t-test computed and the results of paired sample t-test presented that EG significantly improved speed dribbling, and in the $\mathrm{CG}$ indicated that slightly significantly improved speed dribbling observed in between pre-and post-testing and the result of independent sample t-test indicated that EG significantly improved than CG observed in post-testing. The finding of the current study is matched with the research finding of Ezhilmaran that the specific drills with plyometric training group had significantly improved on speed dribbling and passing accuracy of school level handball players due to the effect of specific drills with the plyometric training program [6]. Similarly, Shallaby stated that plyometric exercises have an effect on the speed dribbling skillful performance basketball players [14]. likewise, Baouche et al. (2017) examined that the proposed exercises in the plyometric training method has significantly developed the level of performance of passing accuracy, receiving, speed dribbling and jumping skill of handball players. Against this, Subash (2010) identified that plyometric training had no significantly improved on speed dribbling, passing accuracy, and jumping ability of intercollegiate level men handball players.

The other objective of this study was to examine the effect of plyometric training on passing accuracy. To analyze this, paired sample t-test and independent sample t-test computed and the results of paired sample t-test presented that EG and CG had no significantly improved passing accuracy observed in between pre-and post-testing and the result of the independent sample t-test showed that there is no significant difference in EG and CG observed in post-testing. The finding of the current study is parallel with the research finding of Subash (2010) conducted a study on the effect of plyometric training on selected physical fitness and skill performance variables of intercollegiate level men handball players and the plyometric training group had no significantly improved speed dribbling, passing accuracy, and jumping ability of intercollegiate level men handball players. On the contrary, Baouche et al. (2017) conducted a study on the impact of proposed exercises in the method of plyometric training in the development of explosive power and some basic skills of handball and the proposed exercises in the plyometric training method significantly developed the level of performance of passing accuracy, receiving, dribbling, and jumping skills of handball players.

\section{Conclusions}

Based on the results of the data analyzed, the researcher could reach the following conclusions: The main conclusion to be drawn from the results of the experimental statistics is that there is a significant difference between pretest and posttest result of shooting accuracy and speed dribbling of an experimental group of handball players, but there is no significant difference in passing accuracy due to the intervention of plyometric training. Likewise, based on the major findings of the study, it was concluded that there is no significant difference between pretest and posttest of shooting accuracy and passing accuracy of a control group of handball players, but there is a slightly significant difference in speed dribbling of a control group of handball players.

In addition, based on the results of the statistics is that there is no significant difference in pretest result of passing accuracy, shooting accuracy and speed dribbling variables of handball technical skill performance between the experimental and control group, but there is a significant difference in posttest result of shooting accuracy and speed dribbling dependent variables of handball technical skill performance between the experimental and control group, but then again there is no significant difference in posttest of passing accuracy between an experimental and control group of handball players.

Therefore, according to the result of this study, plyometric training has significantly developed the level of performance of sped dribbling and shooting accuracy technical skill performance of handball players, but it has not significantly developed the level of performance of passing accuracy technical skill performance of handball team players.

\section{Recommendations}

The purpose of the current study was to examine the effects of plyometric training on technical skill performance of handball team players at Debre Markos town. Based on the conclusions drawn in light of the research findings, the subsequent recommendations are forwarded.

\subsection{Recommendation for Practice}

Based on the finding and conclusion of this study the following recommendation will be given:

1) Coaches should use of plyometric training method with a scientific method of training because of its importance in developing some technical skill performance of handball players, and avoid using traditional methods of training.

2) Plyometric training method should not be given more than three days per week.

3) When applying the plyometric training method, the training loads will be based on the players' physical fitness level, training age, age and gender.

4) Coaches should give both upper and lower extremities plyometric exercises for handball team players in order to develop some basic handball skills (shooting accuracy and speed dribbling).

It is necessary to raise awareness of the trainers about the importance of plyometric exercises to improve some technical skill performance of handball players.

\subsection{Recommendation for Further Study}

1) Other researchers should conduct this research on female and male handball players by increasing training week.

2) Other researcher should conduct these training effects 
by incorporating other technical skill of handball rather than passing accuracy, shooting accuracy and speed dribbling.

3) Researcher who have an interest on the area should do research within the comparison of effects of plyometric training other training methods on technical skill performance of handball players.

4) Researchers should conduct this researcher by considering the playing position of handball team players.

5) Other researchers who are interested on this area should try to investigate a research on the effect of other training methods on these technical skill performance of handball players.

\section{References}

[1] Abolghasem, M., Mehrzad, M. \& Karim, Z. (2014). Effects of plyometric training on skill performance in soccer players. International Journal of Current Research and Academic Review, 2 (9), 242-247.

[2] Ali, A., Williams, C., Hulse, M., Strudwick, A., Reddin, J., Howarth, L., Eldred, J., Hirst, M. \& McGregor, S. (2007). Reliability and validity of two test of handball skill. Journal of Sport Science, 25 (13), 1461- 1470.

[3] Baouche, K, Laidani, H., Baizid, A., \&Saidi, A. (2017). The impact of proposed exercises in the method of plyometric training in the development of explosive power and some basic skills of handball. European Journal of Physical Education and Sport Science, 3.

[4] Barbara, S. (2011). Team Handball. The Canadian Encyclopedia. Historica-Dominion institute.

[5] Erčulj, F., \&Supej, M. (2006). The impact of fatigue on jump shot height and accuracy over a long shooting distance in handball. Journal of Sport Science, 63, 35-41.

[6] Ezhilmaran, N. (2016). Effect of specific drills with plyometric training on selected skill performance variables of school level men handball players. Indian Journal of Applied Research, 6 (7), 24-25.

[7] Gursharan, G. (2017). Effects of 12 week SAQ training program on handball skill variables of handball player's. International Journal of Research Pedagogy and Technology in Education and Movement Sciences, 5.

[8] Hartz, C., Sindorf, M., Lopes, C., Batista, J., \& Moreno, M. (2018). Effect of plyometric training on the performance of handball athletes. Journal of Human Kinetics, 63, 43-51.

[9] Kamar, A. (2008). Talent, skill and performance tests in sports. Ankara: Nobel.
[10] Miller, M., Berry, C., Bullard, S., \& Gilders, R. (2002). Comparisons of land-based and aquatic based plyometric programs during an 8-week training period. Journal of Sport Rehabilitation, 11, 269-283.

[11] Mohamed, H., Vaeyens, R., Matthys, S., Multail, M., Lefevre, J., Lenoir, M., \& Philppaerts, R. (2009). Anthropometric and performance measures for the development of a talent detection and identification model in youth handball. Journal of Sport Science, 27, 257-266.

[12] Pojskić, H., Šeparović, V., \&Užičanin, E., (2009). Differences between successful and unsuccessful handball teams on the final Olympic tournament. 3, 110-114.

[13] Pojskić, H., Šeparović, V., \&Užičanin, E. (2011). Reliability and validity of handball shooting accuracy tests. Sport Scientific and Practical Aspects, 8, 25-32.

[14] Shallaby, H. (2010). The effect of plyometric exercises on the physical and skillful performance of Basketball Players. World Journal of Sport Sciences, 3 (4), 316-324.

[15] Subash. P. (2010). The effects of plyometric training on selected physical fitness and skill performance variables of inter collegiate level men handball players.

[16] Surendra, S. (2018). Study the effects of plyometric and functional training program on jumping and shooting abilities of handball players. School of Educational Sciences. Swami Raman and Teerth Marathwada University, Nanded.

[17] Suresh, K., Mohan, K., \&Rajeswaran. (2014). Effect of handball specific skill training on selected skills and over all playing ability of inter-collegiate men handball players. Journal of Academic Sports Scholar, 3, 2277-3665.

[18] Tillaar, R., \& Ettema, G. (2007). A three-dimensional analysis of over arm throwing in experience handball players. Journal of Applied Biomechanics, 23, 12-19.

[19] Umeshraj, P. (2012). Development of norms for selection of senior male Maharashtra state hand ball players. university of pune physical education.

[20] Van den Tillaar, R. (2004). Effect of different training program on the velocity of overarm throwing. Journal of Strength and Conditioning Research, 18, 388-396.

[21] Yahya, H., Bahador, I., \& Mohammad, H. (2014). Effect of 8week plyometric exercise on some of factors physical fitness and motor skills of handball players. Indian Journal of Fundamental and Applied, 4 (4), 1820-1823.

[22] Yogesh, B. (2012). Development of skill tests of team handball for junior level male handball players of maharashtra.

[23] Zapartidis, I., Panagiotis, K., Christodoulidis, T., Skoufas, D., \&Bayios I. (2011). Profile of young handball players by playing position and determinants of ball throwing velocity. Journal of Human Kinetics, 27, 17-30. 